\title{
95 Percent Maximal Inhibitory Concentration Fold Change from Reference Measurement
}

National Cancer Institute

\section{Source}

National Cancer Institute. 95 Percent Maximal Inhibitory Concentration Fold Change from

Reference Measurement. NCI Thesaurus. Code C116253.

A fold change based on a concentration of a specific drug expected to produce 95\% inhibition of the standard growth of a viral organism, or of a biological/biochemical reaction. It is a ratio calculated by the IC95 T reatment Result divided by the IC95 Reference Control Result. 